\title{
Assessment of knowledge attitude and practice towards hepatitis B among health care workers in a tertiary care hospital
}

\author{
Farhana Siraj $^{1}$, Perveena Fareed ${ }^{2}$, Neha Mahajan ${ }^{2} *$
}

\author{
${ }^{1}$ Department of General Medicine, LD Hospital, Govt. medical college, Srinagar, J\&k, India \\ ${ }^{2}$ Department of Obstetrics and Gynaecology, LD Hospital, Govt. medical college, Srinagar, J\&k, India
}

Received: 17 September 2015

Revised: 01 December 2015

Accepted: 14 December 2015

\section{*Correspondence:}

Dr. Neha Mahajan,

E-mail: doctor3086@gmail.com

Copyright: (C) the author(s), publisher and licensee Medip Academy. This is an open-access article distributed under the terms of the Creative Commons Attribution Non-Commercial License, which permits unrestricted non-commercial use, distribution, and reproduction in any medium, provided the original work is properly cited.

\begin{abstract}
Background: Hepatitis B is caused by infection with hepatitis B virus and is a major global health burden. In India, the prevalence of Hepatitis B in general population is $2-10 \%$, which place India in an intermediate endemic zone and second largest global pool of chronic hepatitis B infection. Among health care workers Hepatitis B prevalence is two to four folds higher than that of the general population. Transmission of hepatitis B occurs from infected person through blood transfusion; needle pricks unprotected sexual intercourse, sharing of eating utensils and other barber shop and beauty salon equipment. To curb HBV infection prevention programs must be implemented and the complete vaccination schedule must be followed. The objective of the study was to assess the Knowledge attitude and practice towards Hepatitis B among health care workers in a tertiary care hospital.

Methods: This cross sectional prospective study was done in the Department of Obstetrics and Gynecology GMC Srinagar. Information about the socio-demographic characteristics, knowledge towards transmission and prevention method of hepatitis B was taken from 150 health care workers including medical and paramedical staff of the hospital. Results: This cross sectional prospective study was conducted in the Department of Obstetrics and Gynecology Govt. Medical College Srinagar from January to June 2015. 150 health care professionals were taken for the study. Knowledge regarding disease and transmission was fairly good. Regarding vaccination status $42.02 \%$ of medical and $29.60 \%$ of paramedical staff was fully vaccinated, the most common reason for non compliance being ignorance of importance of vaccination. Awareness of patients' vaccination status was also low.

Conclusions: Due to low vaccine-compliance, Health care workers (HCW) continue to be at the risk of occupational HBV infection. Regular Health education highlighting occupational risk of HBV, accessibility of vaccine, and mandatory vaccination of $\mathrm{HCW}$ is recommended to prevent Hepatitis B infection.
\end{abstract}

Keywords: Hepatitis B virus, Health care workers, Transmission, Vaccination

\section{INTRODUCTION}

Hepatitis B caused by infection with hepatitis B virus is a major global health burden. This infection affects the liver and is the most common cause of chronic hepatitis, liver cirrhosis and hepato-cellular carcinoma. ${ }^{1}$ Hepatitis B is a public health problem affecting about $10 \%$ of the world population. ${ }^{2}$ More than two billion of the population worldwide have evidence of recent or past HBV infection and there are more than 350 million chronic carriers of this infection. ${ }^{1,3}$ In India the prevalence of hepatitis B infection is between $2-10 \%$ in the studied population. ${ }^{4}$ The number of HBsAg carriers in India has been estimated to be about 40 million. Estimates indicate that annually over 100,000 Indians die because of disease related with HBV infection. ${ }^{5}$ 
Hepatitis B is transmitted from one infected individual to another by blood to blood contact, mother to child, unprotected sexual intercourse, sharing barber shop and beauty salon equipment. $^{6}$

The practice of modern medicine have contributed a lot in rising rate and spreading of blood born diseases like Human immune deficiency virus and HBV due to lapse in the sterilization technique and improper hospital waste management as 10 to $20 \%$ health care waste is regarded hazardous ${ }^{7}$. Among the health care personnel's HBV is transmitted by prick of contaminated needles and syringes or through accidental inoculation of the minute quantities of blood during surgical and dental procedures. Knowledge regarding the Hepatitis $B$ virus and safety precautions is needed to minimize the acquired infections among health workers. They should have the complete knowledge of Hepatitis B infections, importance of vaccinations and practice simple hygienic measures apart from specific protective measures.

A vaccine against hepatitis $B$ has been available since 1982 with the efficacy $85-90 \%$ in preventing infection and the development of chronic disease and liver cancer due to hepatitis B.

\section{METHODS}

This cross sectional prospective study was conducted in the Department of Obstetrics and Gynecology Govt. Medical College Srinagar from January to June 2015. A sample of 150 health care professional including medical and paramedical staff working in the hospital was taken. A structured questionnaire was used to collect information about the socio-demographic characteristics, knowledge towards transmission and prevention method of hepatitis B virus and practice towards prevention HBV. Data was entered and analyzed in SPSS version 16 and was presented in the form of simple graphs.

\section{RESULTS}

A total of 150 health care professionals were taken for the study. Among 150 cases 69 were medical professionals and 81 were Para-Medical workers. The mean age of medical professionals was 27.8 yrs with 9.08 yrs experience in profession. The mean age of paramedical staff was 36.6yrs with 14.7 yrs of experience.

\section{Knowledge regarding disease}

$100 \%$ of medical professionals had knowledge of hepatitis B disease whereas $98.7 \%$ paramedical professionals had the same knowledge.

\section{Knowledge regarding transmission}

$100 \%$ of medical professionals had correct knowledge regarding all modes of transmission. However knowledge regarding transmission was less in paramedical professionals. Knowledge regarding sexual route was $83 \%$, needles and syringes $72 \%$, blood transfusion $95 \%$ and vertical transmission $70 \%$.

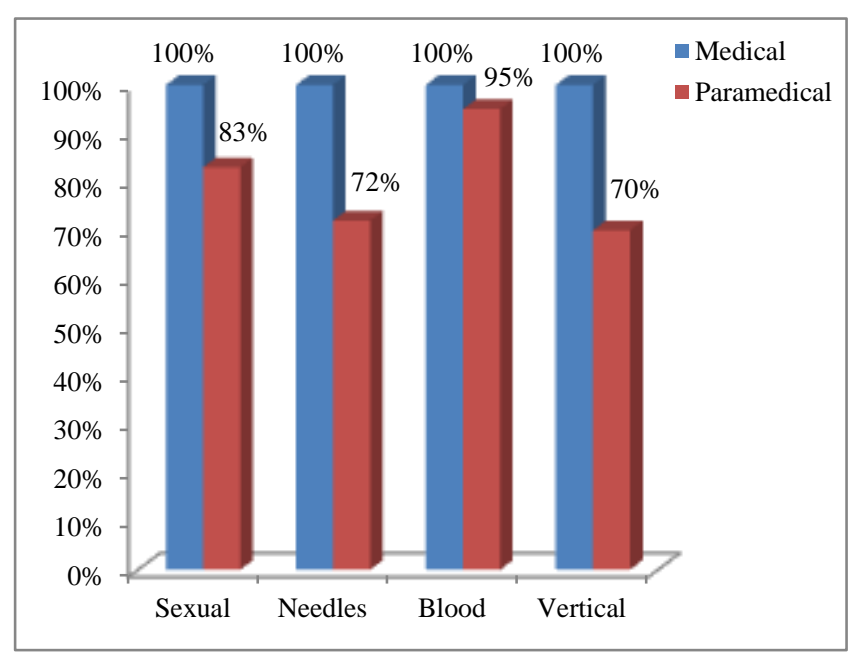

Figure 1: Knowledge regarding routes of transmission.

\section{Source of infection}

$99 \%$ of medical professionals and $98 \%$ of paramedical professionals were at risk of getting disease. In medical staff $98 \%$ were at risk of needle pricks, $86 \%$ to blood and body fluids. In paramedical staff $78 \%$ were at risk of infection with blood and body fluids, $28 \%$ at risk of needle pricks.

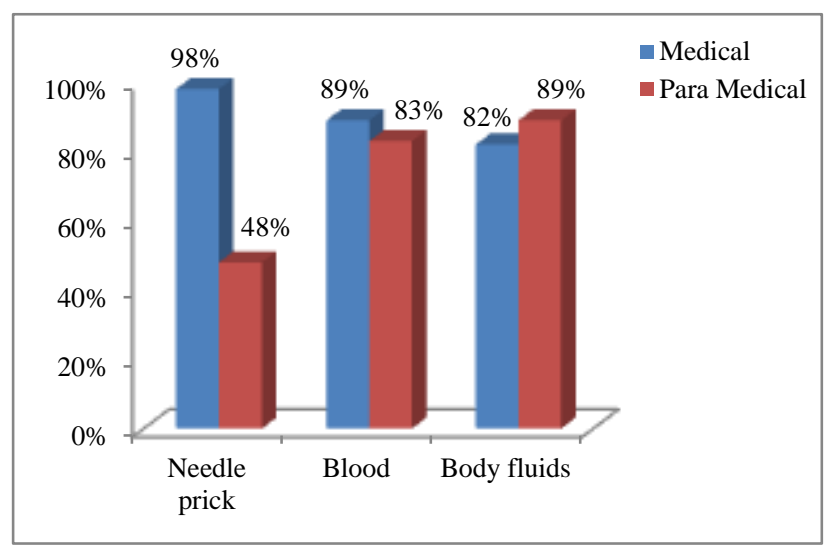

Figure 2: Sources of infection.

\section{Vaccination status}

$55(79.7 \%)$ of medical staff was vaccinated. Among them $29(42.02 \%)$ had taken 3 doses whereas 26(47\%) had taken only 2 doses. Among vaccinated $88 \%$ had taken it within past $5 \mathrm{yrs}, 8 \%$ within $5-10 \mathrm{yrs}$ and $4 \%$ before $10 \mathrm{yrs}$.

$48(59.25 \%)$ of paramedical staff was vaccinated. Among them 24(24\%) had taken 3 doses, 18(18\%) had taken 2 
doses whereas $6(6 \%)$ had taken only 1 dose. Among vaccinated $79 \%$ had taken it within past $5 \mathrm{yrs}, 12 \%$ within 5-10 yrs and 9\%before 10yrs.

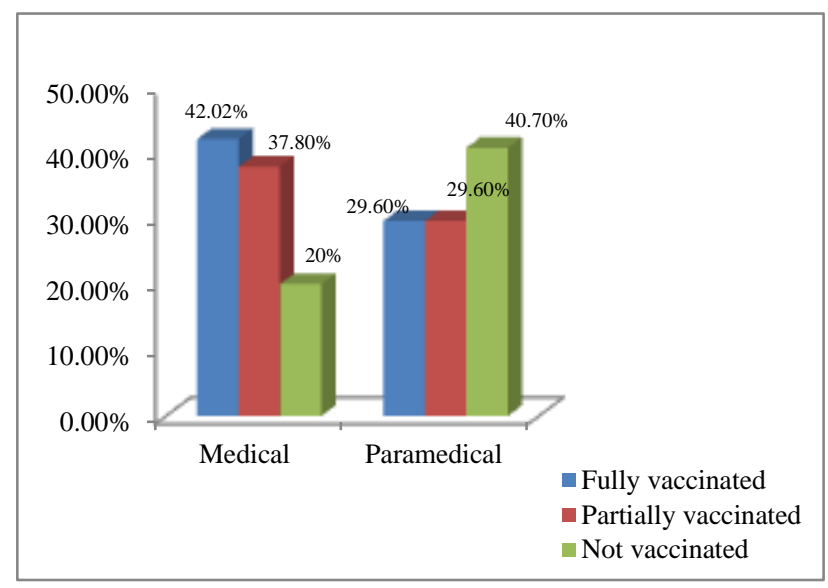

Figure 3: Vaccination status.

\section{Reason for not taking vaccination}

$14(20 \%)$ medical professionals had not taken vaccination. When asked about reason $84 \%$ had ignored vaccination in spite of awareness whereas $16 \%$ had non availability of vaccine.

$33(40.70 \%)$ of paramedical staff were not vaccinated. Reason for non- compliance being ignorance (72\%), non availability of vaccine (12\%) and lack of awareness $(16 \%)$.

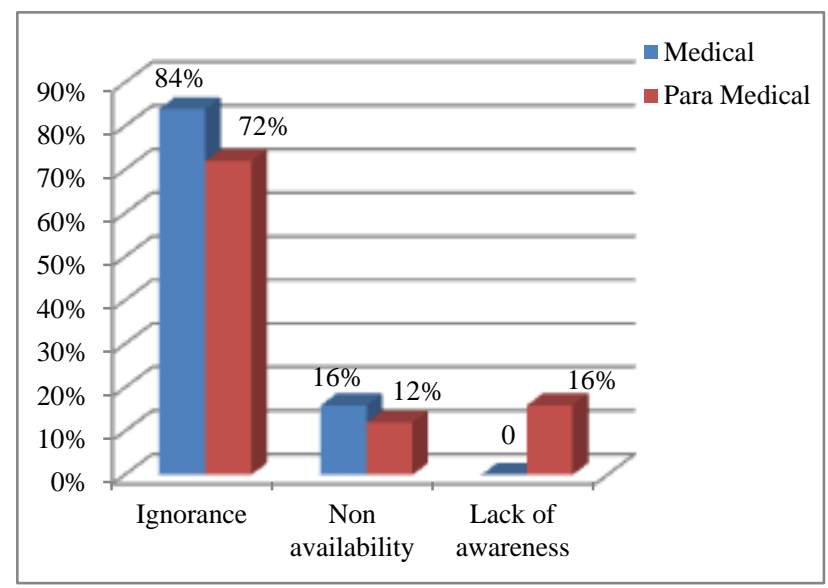

Figure 4: Reason for not getting vaccinated.

\section{Knowledge about patient's Hepatitis B Status}

Only $25 \%$ medical staff was aware, $71 \%$ is occasionally aware and $4 \%$ not aware about patient's hepatitis B status.

In Para Medical staff $20 \%$ was aware, $66 \%$ is occasionally aware, whereas $14 \%$ not aware about patient's hepatitis B status.

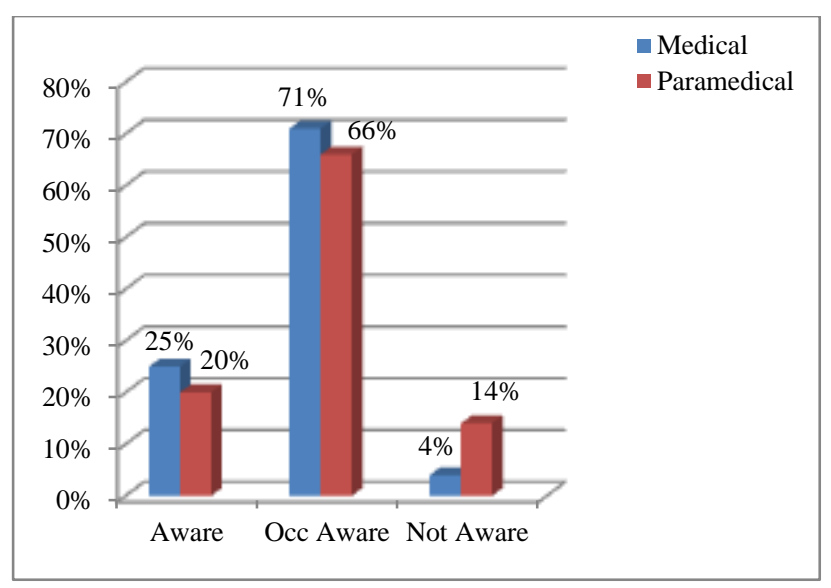

Figure 5: Awareness of patients' hepatitis B status.

\section{Knowledge about own Hepatitis B status}

$56.52 \%$ Medical professionals knew their own hepatitis B status whereas only $32.09 \%$ Para Medical professionals had checked their hepatitis B status.

\section{DISCUSSION}

The current study was sought to evaluate knowledge and practice towards Hepatitis B among medical and paramedical staff working in the Department of obstetrics and Gynaecology GMC Srinagar. The Knowledge regarding epidemiology of Hepatitis B was fairly good in medical staff compared to paramedical staff $(100 \% \mathrm{v} / \mathrm{s}$ 98.7\%).Knowledge about HBV transmission is essential for health care workers so that they can take proper protection during their clinical practice as $\mathrm{HBV}$ is 50 times easier to transmit than HIV. ${ }^{9}$ The study revealed that there was good knowledge regarding transmission in medical staff whereas $83 \%$ of paramedical staff had knowledge regarding sexual route, $72 \%$ Needles pricks, $75 \%$ blood and $70 \%$ vertical transmission. Avjot Mighlani ${ }^{10}$ in his study found $100 \%$ awareness in doctors regarding transmission of disease whereas $82 \%$ nurses and $80 \%$ lab technicians had knowledge regarding Hepatitis B transmission.

In the present study medical staff had better knowledge regarding prevention of $\mathrm{HBV}$ as compared to Para medical staff. Regarding post exposure prophylaxis only $63 \%$ of medical staff and $43 \%$ Para medical staff were aware which calls for well structured health education programs. Sowmya Kasetty et al ${ }^{11} 82.15 \%$, 95.36\%, $58.22 \%$ and $93 \%$ had good knowledge about hepatitis infection and its transmission, vaccine, attitude towards HBV patients and post exposure prophylaxis respectively.

In the present study $42 \%$ of medical staff was fully vaccinated, $37 \%$ partially vaccinated and $20 \%$ not vaccinated at all. In paramedical staff only $29 \%$ were fully vaccinated, $29 \%$ partially vaccinated and $40 \%$ not vaccinated at all. The various reasons for not getting 
vaccinated were ignorance $(84 \% / 72 \%)$ followed by non availability of vaccine and lack of awareness. Sumit Kumar, Rehana Begum et $\mathrm{al}^{12}$ in their study found $46.2 \%$ HCW fully vaccinated, $12 \%$ partially vaccinated and $41 \%$ not vaccinated. Shagufta Hussain ${ }^{13}$ et al in their study had complete immunization rate of $57.6 \%$, partial $18.5 \%$ and non vaccinated $24 \%$.Subhash Chandra et al $^{14}$ had overall proportions of complete, incomplete and unvaccinated respondents with hepatitis $\mathrm{B}$ vaccine as $48.5 \%, 21.8 \%$ and $29.7 \%$ respectively.

Regarding knowledge of patient's Hepatitis B status only $25 \%$ of medical and $20 \%$ of paramedical staff are aware. $71 \%$ of medical staff and $66 \%$ of Para medical staff are occasionally aware about patients' status. This lack of awareness was due to high rush of unbooked and uninvestigated patients and lack of immediate testing.

$56.52 \%$ of medical staff had done testing for Hepatitis B status whereas $32.03 \%$ of paramedical staff had done their own testing. Shagufta Hussain et $\mathrm{al}^{13}$ in their study found that $93.7 \%$ knew about their own Hepatitis B status while $6.3 \%$ had never got themselves tested for hepatitis B.

\section{CONCLUSIONS}

Our study highlights low and delayed vaccine compliance in health care workers leading to continued occupational risk of Hepatitis B Virus (HBV). Attitude, knowledge of HBV infection and accessibility of HBV vaccine were important factors in low and delayed vaccination in health care workers. The study recommends regular health education programmes of HCWs on occupational risk of $\mathrm{HBV}$ and mandatory vaccination of $\mathrm{HCW}$ in prevention of HBV infection. Medical colleges should have occupational health departments that take responsibility of $\mathrm{HBV}$ testing, vaccination, response monitoring and providing post exposure prophylaxis. It is also recommended to make vaccines available and accessible.

\section{Funding: No funding sources}

Conflict of interest: None declared

Ethical approval: The study was approved by the Institutional Ethics Committee

\section{REFERENCES}

1. World Health Organization (2011) Hepatitis B. Fact sheet no:204 Available:http://www.who.int/mediacentre/factsheets /fs204/en Accessed 2015 July 06.

2. Park JE, Park K. Text Book of Preventive and Social Medicine, 19th Edition. M.S. Banarsidas Bhanot. 2007;267.
3. Samuel SO, Aderibigbe SA, Salami TA, Babatunde OA. Health workers' knowledge, attitude and behavior towards hepatitis B infection in Southern Nigeria. Int J Med Sci. 2009;1:418-24.

4. Tandon BN, Acharaya SK, Tandon A. Epidemiology of Hepatitis B virus infection in India. Gut. 1996;38(2):56-9.

5. Taneja N, Biswal M. Rapid Assessment of Hepatitis $B$ Vaccine Introduction in India. Proposal for INS support: India-GAVI Alliance. 2004. Aug 1st-6th, Last accessed on 2013 Sep 10. www.gavialliance.org/country/india/documents.

6. Yayehyirad K, Asfaw D, Hailemariam K, Mengistu A, Binyam A. Of Institutions and Persons. Ethio. J. Health Dev. 2009;23:173-223.

7. Taneja N, Biswal M. Safe disposal of infectious waste.. Indian perspective Journal of Hospital Infection. 2009;62(4):525-26.

8. Muhammad SM, Shoaib A, Rashid N, Naresh KK, Mukhtar AM. Hepatitis B vaccination status in health care worker of two university hospitals. J LUMHS. 2007:48-51.

9. Centers for Disease Control and Prevention. Summary of notifiable diseases, United States, MMWR Morb Mortal Wkly Rep. 1997;45:74-9.

10. Avjot Mighlani. Knowledge and Awareness Regarding Hepatitis B Vaccination among Medical Fraternity. International Journal of Basic and Applied Medical Sciences. 2014;4(2):99-102.

11. Kasetty S, Mohania A, Dwivedi D, Tijare M, Kallianpur S, Gupta S. A Cross-Sectional Study on the Knowledge of Hepatitis B Infection among Dental Professionals. Journal of Virology \& Microbiology 2013. DOI: 10.5171/2013.288280.

12. Kumar S, Begum R, Umar U, Kumari P. Hepatitis B Seropositivity and Vaccination Coverage among Health Care Workers in a Tertiary Care Hospital in Moradabad, UP, India. International Journal of Scientific Study. 2014;1:4.

13. Hussain S, Patrick NA, Shams R. Hepatitis B and C Prevalence and Prevention Awareness among Health Care Workers in a Tertiary Care Hospital. International Journal of Pathology. 2010;8(1):16-21.

14. Chandra S, Joshi Go, Singh Y. Hepatitis B vaccination status among healthcare workers in a tertiary care hospital in Haldwani City of Nainital, Uttarakhand, India. Ann Trop Med Public Health. 2014;2(7):96-9.

Cite this article as: Siraj F, Fareed P, Mahajan N. Assessment of knowledge attitude and practice towards hepatitis B among health care workers in a tertiary care hospital. Int J Reprod Contracept Obstet Gynecol 2016;5:58-61. 